\title{
Frozen elephant trunk with total arch replacement for type A aortic dissections: Does acuity affect operative mortality?
}

\author{
Wei-Guo Ma, MD, ${ }^{\mathrm{a}, \mathrm{b}, \mathrm{c}}$ Jun Zheng, MD, ${ }^{\mathrm{a}, \mathrm{b}}$ Wei Zhang, MD, ${ }^{\mathrm{a}}$ Kai Sun, MD, PhD, ${ }^{\mathrm{b}}$ Bulat A. Ziganshin, MD, \\ Long-Fei Wang, MD, ${ }^{\mathrm{a}}$ Rui-Dong Qi, MD, ${ }^{\mathrm{a}, \mathrm{b}}$ Yong-Min Liu, MD, ${ }^{\mathrm{a}, \mathrm{b}}$ Jun-Ming Zhu, MD, ${ }^{\mathrm{a}, \mathrm{b}}$ \\ Qian Chang, MD, ${ }^{\mathrm{b}}$ John A. Elefteriades, $\mathrm{MD},{ }^{\mathrm{c}}$ and Li-Zhong Sun, $\mathrm{MD}^{\mathrm{a}, \mathrm{b}}$
}

\begin{abstract}
Objective: We seek to compare the early outcomes of frozen elephant trunk with total aortic arch replacement using a 4-branched graft (the Sun procedure) in patients with acute and chronic type A aortic dissection (TAAD), identify the risk factors for operative mortality, and determine whether the acuity of TAAD significantly affects operative mortality.
\end{abstract}

Methods: We performed univariate and multivariate analyses of the clinical data from 803 patients with TAAD who underwent the Sun procedure.

\begin{abstract}
Results: The operative mortality was $6.5 \%$ (52 of 803). The overall incidence of stroke and spinal cord injury was $2.0 \%$ (16 of 803$)$ and $2.4 \%$ (19 of 803), respectively. Patients with acute TAAD had a greater incidence of operative death $(8.1 \%$ vs $4.3 \% ; P=.031)$, stroke $(2.2 \%$ vs $0.6 \% ; P=.046)$, and respiratory morbidities $(20.8 \%$ vs $8.6 \% ; P<.001)$. However, acuity was not identified as a risk factor for operative mortality (odds ratio [OR], $1.67 ; P=.152)$. The risk factors were previous cerebrovascular disease $(\mathrm{OR}, 7.01 ; P=.001)$; malperfusion of the brain (OR, 7.10; $P=.002)$, kidneys (OR, 12.67; $P=.005)$, spinal cord $(\mathrm{OR}, 22.79$; $P=.008)$, and viscera (OR 22.98; $P=.002)$; concomitant extra-anatomic bypass (OR, $9.50 ; P<.001)$; and cardiopulmonary bypass time $>180$ minutes $(\mathrm{OR}, 1.01 ; P<.001)$.

Conclusions: In this group of patients with type A dissection, acuity was not a risk factor for operative mortality after the Sun procedure. Patients with previous cerebrovascular disease; malperfusion of the brain, kidneys, spinal cord, and/or viscera; concomitant extra-anatomic bypass; and a longer cardiopulmonary bypass time (>180 minutes) were at greater risk of operative mortality. (J Thorac Cardiovasc Surg 2014;148:963-72)
\end{abstract}

Stanford type A aortic dissection (TAAD) remains one of the most lethal conditions and is associated with significant morbidity and mortality. The patient is at the greatest risk in the acute phase, within 14 days of the initial event, when

\footnotetext{
From the Department of Cardiovascular Surgery, ${ }^{a}$ Beijing Aortic Disease Center, Beijing Anzhen Hospital of Capital Medical University, Beijing Institute of Heart, Lung and Blood Vessel Diseases, and Beijing Engineering Research Center of Vascular Prostheses, Beijing, China; Fu Wai Hospital and Cardiovascular Institute, ${ }^{\mathrm{b}}$ Chinese Academy of Medical Sciences and State Key Laboratory of Cardiovascular Disease, National Center for Cardiovascular Disease, Beijing, China; and Aortic Institute at Yale-New Haven, ${ }^{c}$ Yale University School of Medicine, New Haven, Conn.

This study was supported in part by the International Science and Technology Cooperation Program of China (grant 2012DFA31110) and Project of Healthcare Professional Leadership in Beijing (grant 2011-1-3).

Disclosures: John A. Elefteriades reports consulting fees from Cryolife, Covidien, and Datascope; equity ownership in Coolspine; and grant funding from the National Marfan Foundation. All other authors have nothing to disclose with regard to commercial support.

Read at the 94th Annual Meeting of The American Association for Thoracic Surgery, Toronto, Ontario, Canada, April 26-30, 2014.

Wei-Guo Ma and Jun Zheng contributed equally to this work.

Received for publication April 16, 2014; revisions received May 31, 2014; accepted for publication June 4, 2014; available ahead of print July 17, 2014.

Address for reprints: Li-Zhong Sun, MD, Department of Cardiovascular Surgery, Beijing Anzhen Hospital of Capital Medical University, Beijing Institute of Heart,

Lung and Blood Vessel Diseases, 2 Anzhen Rd, Beijing 100029, China (E-mail:

lizhongsun@outlook.com).

$0022-5223 / \$ 36.00$

Copyright (C) 2014 by The American Association for Thoracic Surgery

http://dx.doi.org/10.1016/j.jtcvs.2014.06.005
}

complications resulting from hemorrhage or rupture are most likely. ${ }^{1,2}$ Although the past 2 decades have seen advances in surgical techniques and postoperative care, evidence for improved outcomes has been modest, ${ }^{3}$ and several contentious issues remain in the surgical treatment of patients with TAAD. The most fundamental issue is the optimal surgical approach, especially the extent of the distal aortic repair. ${ }^{4-6}$ Some surgeons have advocated a more limited approach, such as ascending aortic or hemiarch repair, ${ }^{6}$ and others have supported the frozen elephant trunk (FET) technique, ${ }^{7-9}$ which has considerably improved the clinical outcomes of TAADs involving the aortic arch and proximal descending aorta. ${ }^{10,11}$ However, surgical opinion has been divided on the use of this extensive approach for patients with TAAD. ${ }^{3,7,8,12,13}$ The event of acute dissection itself is the dominant risk factor, just as is the need for preoperative resuscitation. ${ }^{3,14}$ This raises another concern that surgical repair in the acute phase is associated with greater operative mortality than in the chronic phase, which was evidenced by the report of Safi and colleagues, ${ }^{1}$ which showed an operative mortality of $20 \%$ in those with acute and $4 \%$ in those with chronic TAAD.

For those reasons, we retrospectively analyzed the early outcomes of FET with total aortic arch replacement using a 4-branched graft (ie, the Sun procedure) ${ }^{15-18}$ in 803 


\section{Abbreviations and Acronyms \\ $\mathrm{CPB}=$ cardiopulmonary bypass \\ FET $=$ frozen elephant trunk \\ $\mathrm{OR}=$ odds ratio \\ $\mathrm{TAAD}=$ type $\mathrm{A}$ aortic dissection}

consecutive patients with TAAD treated by our group. We compared the early outcomes between the acute and chronic TAAD groups after the Sun procedure to identify the risk factors for operative mortality in both groups and whether the acuity of aortic dissection significantly affects the operative mortality with this extensive surgical approach for TAADs.

\section{METHODS}

The ethics committees of Fu Wai Hospital and Cardiovascular Institute and Beijing Anzhen Hospital, Capital Medical University approved the present retrospective study.

\section{Patients}

From April 2003 to September 2012, our group performed the Sun procedure for 803 patients with TAAD. Their mean age was $46.1 \pm 10.8$ years (range, 17-78), and 640 (79.7\%) were male. Based on the interval between symptom onset and surgery, ${ }^{2}$ acute TAAD ( $\leq 14$ days) was diagnosed in 456 patients and chronic TAAD (>14 days) in 347. In those with acute TAAD, the interval was $5.0 \pm 3.8$ days (median, 4 ; range, 5 hours to 14 days). Also, within the first 10 hours after dissection onset, 30 of the 456 patients $(6.6 \%)$ presented and $6(1.3 \%)$ underwent surgery. The median interval from symptom onset to surgery in those with chronic TAAD was 37 days (mean, 189; range, 14.2 days to 10 years). A preoperative diagnosis of TAAD was confirmed by transthoracic echocardiography or computed tomographic angiography in all patients.

A total of 101 cases $(12.6 \%)$ of clinically apparent malperfusion occurred in 88 patients $(10.9 \%)$, with $56(12.3 \%)$ and $32(9.2 \%)$ in the acute and chronic groups, respectively. Lower limb malperfusion was most common $(6.0 \%, 48$ of 803$)$, followed by cerebral $(2.6 \%, 21$ of $803)$, coronary $(1.7 \%, 14$ of 803$)$, renal $(0.9 \%, 7$ of 803$)$, and visceral ischemia $(0.9 \%, 7$ of 803 ; Table 1$)$.

\section{Selection Criteria}

In patients with TAAD, the Sun procedure was indicated in any of the following pathologic conditions: (1) primary entry located in the arch or descending aorta; (2) severe arch vessel pathologic features, including dissection, occlusion, stenosis, or aneurysm changes; (3) intimal intussusception in the arch; (4) concomitant Marfan syndrome; and (5) dissection in a dilated arch $>4 \mathrm{~cm}$ in diameter and extending beyond the descending aorta. ${ }^{19}$ For patients with none of these conditions, a different approach would be proposed, such as ascending aortic or hemiarch repair or total arch repair without FET. ${ }^{20}$ For patients with TAAD who had the pathologic indications but developed malperfusion preoperatively, this procedure would still be performed, as long as no end-organ failure had occurred, such as coma, paraplegia, hemiplegia, intestinal necrosis, or hepatic failure. Senior age was not a contraindication.

\section{Surgical Techniques}

The Sun procedure refers to total aortic arch replacement using a 4-branched vascular graft combined with implantation of a specially designed FET into the descending aorta. ${ }^{15-18}$ The surgical technique has been previously described in detail. ${ }^{15-23}$ In brief, it is performed with right axillary artery cannulation for cardiopulmonary bypass (CPB) and selective antegrade cerebral perfusion, under moderate hypothermic circulatory arrest at $25^{\circ} \mathrm{C}$. The procedure involves implantation of an FET (Cronus; MicroPort Medical Co, Ltd, Shanghai, China) in the descending aorta, followed by total arch replacement with a 4-branched vascular graft. A special sequence is used for aortic reconstruction (ie, proximal descending aorta, then left carotid artery, then ascending aorta, then left subclavian artery, and, finally, innominate artery). Early rewarming and reperfusion is performed after the distal anastomosis to minimize the cerebral and coronary ischemia. Associated operations, such as aortic root replacement or coronary artery bypass grafting, are performed during the cooling phase, if indicated.

\section{Definition of Outcomes and Risk Factors}

The endpoint was operative mortality, including all deaths, regardless of cause, occurring during the same hospitalization in which the operation was performed, even if after 30 days; and after discharge from the hospital but within 30 postoperative days. Stroke was defined as any confirmed neurologic deficit of abrupt onset caused by a disturbance in blood supply to the brain lasting $>24$ hours. Coronary artery disease was documented by preoperative computed tomographic angiography or from a history of myocardial infarction or coronary angiographic findings, or percutaneous coronary interventions. Renal failure was defined as an increase in serum creatinine of $1 \mathrm{mg} / \mathrm{dL}$ greater than baseline or a new requirement for renal dialysis. Malperfusion syndrome was defined as end-organ ischemia caused by branch vessel involvement and resulting in clinical symptoms and functional impairment.

\section{Statistical Analysis}

The data were analyzed using the Statistical Package for Social Sciences for Windows, version 13.0 (SPSS Inc, Chicago, Ill). Data are expressed as the mean \pm standard deviation or percentages and were compared using the Student $t$ test, Pearson chi-square test, or Fisher exact test, as appropriate. Univariate analysis was used to evaluate variables that could affect operative mortality in both groups. Variables with $P<.05$ on univariate analysis were assessed with multivariate analysis using a forward stepwise binary logistic regression model. All statistical tests were 2-sided.

\section{RESULTS \\ Operative Data}

The location of an intimal tear was confirmed during surgery (Table 2). An intimal tear in the aortic arch was found only in the patients with acute TAAD $(n=92$, $20.2 \%$ ). The patients with chronic TAAD had more tears in the descending aorta (106 of $347,30.5 \%$ ) than did those with acute TAAD $(101$ of $456,22.1 \% ; P=.007)$ and had more unidentifiable tears ( 43 of $347,12.4 \%$ ) than did those with acute TAAD (17 of $456,3.7 \% ; P>.001)$. Aortic root or valve procedures were performed in 221 patients $(48.5 \%)$ with acute and 163 patients $(47.0 \%)$ with chronic TAAD, including aortic valve repair in $63(13.8 \%)$ and $22(6.3 \% ; P=.001)$ and the Bentall operation in 130 $(28.5 \%)$ and $119(34.3 \%)$, respectively. A total of 109 concomitant operations were done in 102 patients $(12.7 \%)$, including coronary artery bypass grafting in 43 $(9.4 \%)$ and $24(6.9 \%)$, extra-anatomic bypass in 11 $(2.5 \%)$ and $16(4.6 \%)$, and mitral valve surgery in 2 $(0.4 \%)$ and $13(3.7 \%)$ patients in the acute and chronic groups, respectively. The $\mathrm{CPB}$, crossclamp, and selective 
TABLE 1. Preoperative clinical profiles

\begin{tabular}{|c|c|c|c|}
\hline Variable & $\begin{array}{c}\text { Acute } \\
(n=456)\end{array}$ & $\begin{array}{c}\text { Chronic } \\
(n=347)\end{array}$ & $\begin{array}{c}P \\
\text { value }\end{array}$ \\
\hline Age $(y)$ & $46.2 \pm 10.5$ & $45.9 \pm 11.2$ & .063 \\
\hline Age group (y) & & & .750 \\
\hline$<40$ & $126(27.6)$ & $100(28.8)$ & .711 \\
\hline $40-49$ & $156(34.2)$ & $112(32.3)$ & .565 \\
\hline $50-59$ & $127(27.9)$ & $92(26.5)$ & .673 \\
\hline$\geq 60$ & $47(10.3)$ & $43(12.4)$ & .554 \\
\hline Sex & & & .026 \\
\hline Male & $376(82.5)$ & $264(76.1)$ & \\
\hline Female & $80(17.5)$ & $83(23.9)$ & \\
\hline \multicolumn{4}{|l|}{ Comorbidities } \\
\hline Hypertension & $333(73.0)$ & $228(65.7)$ & .025 \\
\hline Marfan syndrome & $34(7.5)$ & $52(15.0)$ & .001 \\
\hline Diabetes mellitus & $14(3.1)$ & $10(2.9)$ & .877 \\
\hline Coronary artery disease & $18(3.9)$ & $31(8.9)$ & .003 \\
\hline Cerebrovascular disease & $12(2.6)$ & $11(3.2)$ & .650 \\
\hline Chronic kidney disease & $10(2.2)$ & $10(2.9)$ & .535 \\
\hline Congestive heart failure & $1(0.2)$ & $2(0.6)$ & .812 \\
\hline Malperfusion syndrome* & $56(12.3)$ & $32(9.2)$ & .169 \\
\hline Cerebral malperfusion & $13(2.8)$ & $8(2.3)$ & .631 \\
\hline Coronary malperfusion & $9(2.0)$ & $5(1.4)$ & .568 \\
\hline Renal malperfusion & $7(1.5)$ & $0(0)$ & .053 \\
\hline Spinal cord malperfusion & $3(0.6)$ & $1(0.3)$ & .817 \\
\hline Visceral malperfusion & $6(1.3)$ & $1(0.3)$ & .243 \\
\hline Lower limb malperfusion & $27(5.9)$ & $21(6.0)$ & .938 \\
\hline$\geq 2$ Organs & $8(1.8)$ & $4(1.2)$ & .486 \\
\hline Acute heart failure & $7(1.5)$ & $0(0)$ & .053 \\
\hline Cardiac tamponade & $15(3.3)$ & $1(0.3)$ & .003 \\
\hline
\end{tabular}

Data presented as mean \pm standard deviation or $\mathrm{n}(\%)$. *Number of patients in whom clinically apparent malperfusion occurred; malperfusion of $\geq 2$ organs expressed by the number of cases that actually occurred.

cerebral perfusion times in the acute group were remarkably longer than the those in the chronic group $(199 \pm 50$ vs 184 \pm 52 minutes, $P<.001 ; 112 \pm 47$ vs $98 \pm 29$ minutes, $P<.001$; and $25 \pm 8$ vs $24 \pm 8$ minutes, $P=.038$, respectively). Prolonged aortic crossclamp ( $>100$ minutes) and CPB (>180 minutes) times occurred predominantly in the acute group $(P<.001)$.

\section{Operative Mortality and Morbidity}

The overall operative mortality was $6.5 \%$ (52 of 803), including 15 deaths $(4.3 \%)$ in the chronic and $37(8.1 \%)$ in the acute group, respectively $(P=.031)$. The leading cause of death was multiorgan failure, identified in 24 of the 52 patients $(46.2 \%)$; of the 24 deaths, 16 were in the acute TAAD group (3.5\% of 456$)$. Stroke and low cardiac output syndrome led to $9(2.0 \%)$ and $7(1.5 \%)$ deaths in the acute group compared with $1(0.3 \%)$ and $3(0.9 \%)$ deaths in the chronic group. Three patients $(0.4 \%)$ died of acute renal failure. Other causes of death included respiratory failure, cardiac arrest, mediastinal infection, abdominal aortic rupture, and coagulopathy $(\mathrm{n}=1$ for each; Table 3).
TABLE 2. Operative data

\begin{tabular}{|c|c|c|c|}
\hline Variable & $\begin{array}{c}\text { Acute } \\
(\mathrm{n}=\mathbf{4 5 6})\end{array}$ & $\begin{array}{c}\text { Chronic } \\
(\mathrm{n}=\mathbf{3 4 7})\end{array}$ & $\begin{array}{c}P \\
\text { value } \\
\end{array}$ \\
\hline \multicolumn{4}{|l|}{ Intraoperative findings } \\
\hline Location of intimal tear & & & $<.001$ \\
\hline Ascending aorta & $202(44.3)$ & $152(43.8)$ & .889 \\
\hline Transverse arch & $92(20.2)$ & $0(0)$ & $<.001$ \\
\hline Descending aorta & $101(22.1)$ & $106(30.5)$ & .007 \\
\hline Multiple locations & $44(9.6)$ & $46(13.3)$ & .108 \\
\hline Unidentified & $17(3.7)$ & $43(12.4)$ & $<.001$ \\
\hline \multicolumn{4}{|l|}{ Procedural times } \\
\hline Cardiopulmonary bypass time (min) & $199 \pm 50$ & $184 \pm 52$ & $<.001$ \\
\hline$>180 \min$ & $274(60.1)$ & $165(47.6)$ & $<.001$ \\
\hline Crossclamp time (min) & $112 \pm 47$ & $98 \pm 29$ & $<.001$ \\
\hline$>100 \mathrm{~min}$ & $250(54.8)$ & $136(39.2)$ & $<.001$ \\
\hline Selective cerebral perfusion time (min) & $25 \pm 8$ & $24 \pm 8$ & .038 \\
\hline$>25 \min$ & $157(34.4)$ & $108(31.1)$ & .115 \\
\hline Aortic valve or root procedures & $221(48.5)$ & $163(47.0)$ & .782 \\
\hline Aortic valve repair & $63(13.8)$ & $22(6.3)$ & .001 \\
\hline Repair of sinus of Valsalva & $19(4.2)$ & $6(1.7)$ & .049 \\
\hline David procedure & $1(0.2)$ & $0(0)$ & .999 \\
\hline Aortic valve replacement & $5(1.1)$ & $5(1.4)$ & .909 \\
\hline Bentall procedure & $130(28.5)$ & $119(34.3)$ & .079 \\
\hline Cabrol procedure & $1(0.2)$ & $5(1.4)$ & .115 \\
\hline Wheat procedure & $2(0.4)$ & $6(1.7)$ & .143 \\
\hline Concomitant procedures* & $53(11.6)$ & $49(14.1)$ & .292 \\
\hline Coronary artery bypass grafting & $43(9.4)$ & $24(6.9)$ & .202 \\
\hline Extra-anatomic bypass & $11(2.4)$ & $16(4.6)$ & .087 \\
\hline Ascending aortic-to-femoral & $6(1.3)$ & $9(2.6)$ & .185 \\
\hline Ascending aortic-to-axillary & $1(0.2)$ & $0(0.0)$ & .999 \\
\hline Ascending-to-abdominal aortic & $1(0.2)$ & $2(0.6)$ & .812 \\
\hline Femoral-to-femoral & $3(0.7)$ & $4(1.2)$ & .716 \\
\hline Axillary-to-femoral & $0(0)$ & $1(0.3)$ & .432 \\
\hline Mitral valve operation & $2(0.4)$ & $13(3.7)$ & .001 \\
\hline Replacement & $2(0.4)$ & $10(2.9)$ & .005 \\
\hline Repair & $0(0)$ & $3(0.9)$ & 160 \\
\hline
\end{tabular}

Selective cerebral perfusion time refers to the interval from initiation of hypothermic circulatory arrest to completion of left carotid anastomosis, which is longer than the time for deep hypothermic circulatory arrest, when lower body perfusion is arrested to implant the frozen elephant trunk and suture the proximal descending anastomosis. *Number of patients in whom concomitant procedures were performed; specific procedures are expressed by the number of cases.

Patients with malperfusion had an overall mortality of $19.3 \%$ (17 of 88 ), predominantly in the acute group $(25.0 \%, 14$ of 56 vs $9.4 \%, 3$ of $32 ; P<.001)$. The major reasons were multiorgan failure in 8 , stroke in 4 , low cardiac output syndrome in 2, and acute renal failure in 2 . Malperfusion of $\geq 2$ organs occurred in $8(1.8 \%)$ and 4 $(1.2 \%)$ patients in the acute and TAAD groups, respectively, with 5 deaths $(62.5 \%)$ exclusively in the acute group (Table 4).

The operative mortality rate did not differ significantly, either among 4 age groups in the acute $(P=.185)$ and chronic $(P=.927)$ groups or between the acute and chronic groups in the 4 age groups $(P>.05)$. Patients with acute TAAD who were $\geq 60$ had a mortality of $12.8 \%$ ( 6 of 47 ), 
TABLE 3. Operative mortality and morbidity

\begin{tabular}{lccr}
\hline \multicolumn{1}{c}{ Variable } & $\begin{array}{c}\text { Acute } \\
(\mathbf{n}=\mathbf{4 5 6})\end{array}$ & $\begin{array}{c}\text { Chronic } \\
(\mathbf{n}=\mathbf{3 4 7})\end{array}$ & $\begin{array}{c}\boldsymbol{P} \\
\text { value }\end{array}$ \\
\hline Mortality & $37(8.1)$ & $15(4.3)$ & .031 \\
Multiorgan failure & $16(3.5)$ & $8(2.3)$ & .321 \\
Stroke & $9(2.0)$ & $1(0.3)$ & .070 \\
Low cardiac output syndrome & $7(1.5)$ & $3(0.9)$ & .598 \\
Acute renal failure & $2(0.4)$ & $1(0.3)$ & 1.000 \\
Abdominal aortic rupture & $0(0)$ & $1(0.3)$ & .432 \\
Cardiac arrest & $0(0)$ & $1(0.3)$ & .432 \\
Respiratory failure & $1(0.2)$ & $0(0)$ & 1.000 \\
Mediastinal infection & $1(0.2)$ & $0(0)$ & 1.000 \\
Coagulopathy & $1(0.2)$ & $0(0)$ & 1.000 \\
Morbidity & & & \\
Neurologic & $28(6.1)$ & $16(4.6)$ & .345 \\
Stroke & $13(2.8)$ & $3(0.9)$ & .046 \\
Spinal cord injury & $11(2.4)$ & $8(2.3)$ & .941 \\
$\quad$ Paraplegia & $7(1.5)$ & $2(0.6)$ & .201 \\
$\quad$ Paraparesis & $4(0.9)$ & $6(1.7)$ & .449 \\
Recurrent laryngeal nerve injury & $4(0.9)$ & $5(1.4)$ & .679 \\
Pulmonary* & $95(20.8)$ & $30(8.6)$ & $<.001$ \\
Prolonged ventilation & $84(18.4)$ & $26(7.5)$ & $<.001$ \\
Reintubation & $33(7.2)$ & $12(3.5)$ & .021 \\
Pneumonia & $8(1.8)$ & $2(0.6)$ & .242 \\
Pleural effusion & $2(0.4)$ & $0(0)$ & .509 \\
Pneumothorax & $1(0.2)$ & $1(0.3)$ & 1.000 \\
Renal failure & $18(3.9)$ & $9(2.6)$ & .292 \\
Low cardiac output syndrome & $7(0.8)$ & $6(1.7)$ & .829 \\
Limb ischemia & $3(0.7)$ & $4(1.2)$ & .716 \\
Reintervention & $20(4.4)$ & $20(5.8)$ & .374 \\
Reexploration for bleeding & $10(2.2)$ & $15(4.3)$ & .085 \\
Pericardial drainage for effusion & $5(1.1)$ & $2(0.6)$ & .687 \\
Thoracoabdominal aortic replacement & $0(0)$ & $2(0.6)$ & 1.000 \\
Endovascular stent grafting for distal tear & $2(0.4)$ & $1(0.3)$ & 1.000 \\
Axillary-to-axillary bypass & $1(0.2)$ & $0(0)$ & 1.000 \\
Amputation & $1(0.2)$ & $0(0)$ & 1.000 \\
Redo Bentall procedure & $1(0.2)$ & $0(0)$ & 1.000 \\
\hline Nen & & & \\
& & &
\end{tabular}

*Number of patients in whom pulmonary complications occurred; specific morbidities are expressed by the number of cases that actually occurred.

greater than that in the other age groups but without statistical significance $(P=.185$; Table 5$)$.

The patients with acute TAAD had a greater incidence of stroke (13 of $456,2.2 \%$, vs 3 of $347,0.6 \% ; P=.046)$ and respiratory complications ( 95 of $456,20.8 \%$, vs 30 of 347 , $8.6 \% ; P<.001)$. The overall incidence of stroke and spinal cord injury was $2.0 \%$ (16 of 803 ) and $2.4 \%$ (19 of 803 ), respectively. Stroke occurred in $13(2.2 \%)$ and $3(0.6 \%$; $P=.046)$ and caused $9(69.2 \%)$ and $1(33.3 \%)$ deaths in the acute and chronic groups, respectively. Spinal cord injury occurred in $11(2.4 \%)$ and $8(2.3 \%)$ patients with acute and chronic TAAD, respectively $(P>.05)$, including paraplegia in $7(1.5 \%)$ and $2(0.6 \%)$ and paraparesis in 4 $(0.9 \%)$ and $6(1.7 \%)$. Albeit present only in $13(1.6 \%)$ of the 803 patients, low cardiac output syndrome caused 7 of 7 deaths $(100 \%)$ in the acute and 3 of $6(50.0 \%)$ in the
TABLE 4. Mortality in patients with malperfusion syndrome

\begin{tabular}{llll}
\hline Pt. no. & Acuity & \multicolumn{1}{c}{ Malperfusion type } & \multicolumn{1}{c}{ Cause of death } \\
\hline 1 & Acute & Renal & Acute renal failure \\
2 & Acute & Renal, cerebral, visceral & Multiple organ failure \\
3 & Acute & Spinal cord, lower limb & Stroke \\
4 & Acute & Visceral & Stroke \\
5 & Acute & Cerebral, visceral & Multiple organ failure \\
6 & Acute & Spinal cord, lower limb & Multiple organ failure \\
7 & Acute & Lower limb & Multiple organ failure \\
8 & Acute & Cerebral, visceral & Multiple organ failure \\
9 & Acute & Cerebral & Low cardiac output syndrome \\
10 & Acute & Coronary & Low cardiac output syndrome \\
11 & Acute & Cerebral & Stroke \\
12 & Acute & Renal & Acute renal failure \\
13 & Acute & Coronary & Coagulopathy \\
14 & Acute & Coronary & Multiple organ failure \\
15 & Chronic & Cerebral & Multiple organ failure \\
16 & Chronic & Visceral & Multiple organ failure \\
17 & Chronic & Cerebral & Stroke \\
\hline Pt. no., & Patient number &
\end{tabular}

chronic groups. Renal failure occurred in $27(3.4 \%)$, with $18(3.9 \%)$ in the acute and $9(2.6 \%)$ in the chronic group $(P>.05)$. The overall incidence of recurrent laryngeal nerve injury and limb ischemia was $1.1 \%$ (9 of 803) and $0.9 \%$ (7 of 803), respectively. Prolonged ventilation $>48$ hours was required in 84 patients $(18.4 \%)$ in the acute versus $26(7.5 \%)$ in the chronic group $(P<.001)$. Tracheal reintubation occurred in $33(7.2 \%)$ with acute and 12 $(3.5 \%)$ with chronic TAAD $(P=.021)$. Pneumonia occurred in 10 patients $(1.2 \%)$, pneumothorax in 2 $(0.2 \%)$, and pleural effusion in $2(0.2 \%$; Table 3$)$.

Postoperative reintervention was required in 40 patients $(5.0 \%), 20$ in each group. Reexploration for bleeding was required in 25 patients $(3.1 \%)$, and drainage of pericardial effusion in $7(0.9 \%)$. An intimal tear at the distal end of the open stent graft necessitated endovascular stent grafting in 3 cases. Other reoperations included thoracoabdominal aortic repair in 2 patients with chronic TAAD, a redo Bentall procedure for aortic root bleeding in 1, an axillary to axillary bypass for left arm ischemia in 1, and an amputation for left leg thrombotic necrosis in 1 (Table 3).

TABLE 5. Operative mortality specific to age group in acute and chronic groups

\begin{tabular}{|c|c|c|c|c|c|}
\hline \multirow[b]{2}{*}{ Acuity } & \multicolumn{4}{|c|}{$\begin{array}{l}\text { Age group-specific mortality } \\
\text { (deaths/total patients) }\end{array}$} & \multirow{2}{*}{$\begin{array}{c}P \\
\text { value } \\
\end{array}$} \\
\hline & $<40 \mathrm{y}$ & $40-49 y$ & $50-59$ y & $\geq 60 \mathrm{y}$ & \\
\hline $\begin{array}{l}\text { Acute } \\
\qquad(\mathrm{n}=37)\end{array}$ & $9 / 126(7.1)$ & $8 / 156(5.1)$ & 14/127 (11.0) & $6 / 47(12.8)$ & .185 \\
\hline $\begin{array}{l}\text { Chronic } \\
\qquad(\mathrm{n}=15)\end{array}$ & $4 / 100(4.0)$ & $4 / 112(3.6)$ & $5 / 92(5.4)$ & $2 / 43(4.7)$ & .927 \\
\hline$P$ value* & .314 & .543 & .147 & .327 & - \\
\hline
\end{tabular}
between acute and chronic groups. 
TABLE 6. Univariate analysis of operative mortality in acute and chronic groups

\begin{tabular}{|c|c|c|c|}
\hline Variable & $\begin{array}{c}\text { Acute } \\
(\mathrm{n}=\mathbf{4 5 6})\end{array}$ & $\begin{array}{c}\text { Chronic } \\
(\mathrm{n}=347)\end{array}$ & $\begin{array}{c}P \\
\text { value }\end{array}$ \\
\hline Acuity group & $37 / 419(8.8)$ & $15 / 347(4.5)$ & \\
\hline \multicolumn{4}{|l|}{ Sex } \\
\hline Male & $35 / 376(9.3)$ & $11 / 264(4.2)$ & \\
\hline Female & $2 / 80(2.5)$ & $4 / 83(4.8)$ & \\
\hline \multicolumn{4}{|l|}{ Hypertension } \\
\hline Yes & $29 / 333(8.7)$ & $10 / 228(4.4)$ & \\
\hline No & $8 / 123(6.5)$ & $5 / 119(4.2)$ & \\
\hline \multicolumn{4}{|l|}{ Marfan syndrome } \\
\hline Yes & $2 / 34(5.9)$ & $1 / 52(1.9)$ & \\
\hline No & $35 / 422(8.3)$ & $14 / 295(4.7)$ & \\
\hline \multicolumn{4}{|l|}{ Diabetes mellitus } \\
\hline Yes & 0/14 (0) & $0 / 10(0)$ & \\
\hline No & $37 / 442(8.4)$ & $15 / 337(4.5)$ & \\
\hline \multicolumn{4}{|c|}{ Coronary artery disease } \\
\hline Yes & $1 / 18(5.6)$ & $2 / 31(6.5)$ & \\
\hline No & $36 / 438(8.2)$ & $13 / 316(4.1)$ & \\
\hline \multicolumn{4}{|l|}{ Chronic heart failure } \\
\hline Yes & $0 / 1(0)$ & $0 / 2(0)$ & \\
\hline No & $37 / 455(8.1)$ & $15 / 345(4.3)$ & \\
\hline \multicolumn{4}{|c|}{ Cerebrovascular disease } \\
\hline Yes & $4 / 12(33.3)$ & 0/11 (0) & \\
\hline No & $33 / 444(7.4)$ & $15 / 336(4.5)$ & \\
\hline \multicolumn{4}{|l|}{ Chronic renal failure } \\
\hline Yes & $0 / 10(0)$ & $1 / 10(10.0)$ & \\
\hline No & $37 / 446(8.3)$ & $14 / 337(4.2)$ & \\
\hline \multicolumn{3}{|c|}{ Malperfusion (as an entity) } & $<.001$ \\
\hline Yes & $14 / 56(25.0)$ & $3 / 32(9.4)$ & \\
\hline No & $23 / 400(5.8)$ & $12 / 315(3.8)$ & \\
\hline \multicolumn{3}{|l|}{ Renal malperfusion } & $<.001$ \\
\hline Yes & $3 / 7(42.9)$ & $0 / 0(0)$ & \\
\hline No & $34 / 449(7.6)$ & $15 / 347(4.3)$ & \\
\hline \multicolumn{4}{|l|}{ Coronary malperfusion } \\
\hline Yes & 3/9 (33.3) & $0 / 5(0)$ & \\
\hline No & $34 / 447(7.6)$ & $15 / 342(4.4)$ & \\
\hline \multicolumn{3}{|l|}{ Cerebral malperfusion } & $<.001$ \\
\hline Yes & $5 / 13(38.5)$ & $2 / 8(25.0)$ & \\
\hline No & $32 / 443(7.2)$ & $13 / 339(3.8)$ & \\
\hline \multicolumn{3}{|c|}{ Spinal cord malperfusion } & $<.001$ \\
\hline Yes & $2 / 3(66.7)$ & $0 / 1(0)$ & \\
\hline No & $35 / 453(7.7)$ & $15 / 346(4.3)$ & \\
\hline \multicolumn{3}{|l|}{ Visceral malperfusion } & .001 \\
\hline Yes & $4 / 6(66.7)$ & $1 / 1(100)$ & \\
\hline No & $33 / 450(7.3)$ & $14 / 346(4.0)$ & \\
\hline \multicolumn{4}{|c|}{ Lower limb malperfusion } \\
\hline Yes & $3 / 27(11.1)$ & $0 / 21(0)$ & \\
\hline No & $34 / 429(7.9)$ & $15 / 326(4.6)$ & \\
\hline \multicolumn{3}{|c|}{ Malperfusion of $\geq 2$ organs } & .001 \\
\hline Yes & $5 / 8(62.5)$ & $0 / 4(0)$ & \\
\hline No & $32 / 448(7.1)$ & $15 / 343(4.4)$ & \\
\hline \multicolumn{3}{|l|}{ Acute heart failure } & 017 \\
\hline Yes & 2/7 (28.6) & $0 / 0(0)$ & \\
\hline No & $35 / 449(7.8)$ & $15 / 347(4.3)$ & \\
\hline
\end{tabular}

(Continued)
TABLE 6. Continued

\begin{tabular}{|c|c|c|c|}
\hline Variable & $\begin{array}{c}\text { Acute } \\
(n=456)\end{array}$ & $\begin{array}{c}\text { Chronic } \\
(\mathbf{n}=\mathbf{3 4 7})\end{array}$ & $\begin{array}{c}P \\
\text { value }\end{array}$ \\
\hline Cardiac tamponade & & & .002 \\
\hline Yes & $4 / 15(26.7)$ & $0 / 1(0)$ & \\
\hline No & $33 / 441(7.5)$ & $15 / 346(4.3)$ & \\
\hline \multicolumn{4}{|l|}{ Location of intimal tear } \\
\hline Ascending aorta & $15 / 202(7.4)$ & $7 / 152(4.6)$ & .479 \\
\hline Aortic arch & 9/92 (9.8) & $0 / 0(0)$ & .790 \\
\hline Descending aorta & 9/101 (8.9) & $6 / 106(5.7)$ & .171 \\
\hline Multiple tears & $4 / 44(9.0)$ & $0 / 46(0)$ & .601 \\
\hline Unidentified & $0 / 17(0)$ & $2 / 43(4.7)$ & .406 \\
\hline Selective cerebral perfusion time & & & .575 \\
\hline$>25 \mathrm{~min}$ & $14 / 157(8.9)$ & $5 / 108(4.6)$ & \\
\hline$<25$ min & 23/299 (7.7) & $10 / 239(4.2)$ & \\
\hline Crossclamp time & & & .022 \\
\hline$>100$ min & $24 / 250(9.6)$ & $9 / 136(6.6)$ & \\
\hline$<100 \min$ & $13 / 206(6.3)$ & $6 / 211(2.8)$ & \\
\hline Cardiopulmonary bypass time & & & .014 \\
\hline$>180 \mathrm{~min}$ & $28 / 274(10.2)$ & $9 / 165(5.5)$ & \\
\hline$<180 \min$ & $9 / 182(4.9)$ & $6 / 182(3.3)$ & \\
\hline Aortic valve or root procedures & & & .955 \\
\hline Aortic valve repair & $3 / 63(4.8)$ & $0 / 22(0)$ & .243 \\
\hline Repair of sinus of Valsalva & $2 / 19(10.5)$ & $0 / 6(0)$ & 1.000 \\
\hline David procedure & $0 / 1(0)$ & $0 / 0(0)$ & 1.000 \\
\hline Aortic valve replacement & $0 / 5(0)$ & $0 / 5(0)$ & .402 \\
\hline Wheat procedure & $1 / 2(50.0)$ & $0 / 6(0)$ & .487 \\
\hline Cabrol procedure & $0 / 1(0)$ & $0 / 5(0)$ & .518 \\
\hline Bentall procedure & $13 / 130(10.0)$ & $6 / 119(5.0)$ & .373 \\
\hline None & $18 / 235(7.7)$ & $9 / 184(4.9)$ & .955 \\
\hline Concomitant procedures & & & $<.001$ \\
\hline Yes & 9/53 (17.0) & 9/49 (18.4) & \\
\hline No & 28/403 (6.9) & $6 / 298(2.0)$ & \\
\hline Coronary artery bypass grafting & & & .001 \\
\hline Yes & $6 / 43(14.0)$ & $5 / 24(20.8)$ & \\
\hline No & $31 / 413(7.5)$ & $10 / 323(3.1)$ & \\
\hline Mitral valve repair/replacement & & & .976 \\
\hline Yes & $0 / 2(0)$ & $1 / 13(7.7)$ & \\
\hline No & $37 / 454(9.0)$ & $14 / 334(4.2)$ & \\
\hline Extra-anatomic bypass & & & $<.001$ \\
\hline Yes & $5 / 11(45.5)$ & $4 / 16(25.0)$ & \\
\hline No & $32 / 445(7.2)$ & $11 / 331(3.3)$ & \\
\hline
\end{tabular}

Data presented as deaths/total patients (\%).

\section{Univariate and Multivariate Analysis}

Univariate analysis identified 16 variables associated with operative mortality and showed that the risk of operative mortality after the Sun procedure in those with acute TAAD was 1.95 times greater than that in those with chronic TAAD (odds ratio [OR], $1.95 ; 95 \%$ confidence interval [CI], 1.00-3.63; $P=.031$; Table 6). However, multivariate analysis failed to identify acuity as a risk factor (OR, 1.67; 95\% CI, 0.83-3.38; $P=.152$ ). The risk factors for operative mortality were previous cerebrovascular disease (OR, 7.01; 95\% CI, 2.16-22.73; $P=.001$ ); malperfusion of the brain (OR, 7.10; 95\% CI, 2.08-24.21; $P=.002$ ), kidneys 
TABLE 7. Difference in operative mortality between acute and chronic groups was not affected by acuity of aortic dissection but by 7 other risk factors

\begin{tabular}{lrlr}
\hline \multicolumn{1}{c}{ Variable } & OR & \multicolumn{1}{c}{$\mathbf{9 5 \%}$ CI } & $\boldsymbol{P}$ value \\
\hline Group (acute vs chronic) & 1.67 & $0.83-3.38$ & .152 \\
Previous cerebrovascular disease & 7.01 & $2.16-22.73$ & .001 \\
Spinal cord malperfusion & 22.79 & $2.27-228.97$ & .008 \\
Visceral malperfusion & 22.98 & $3.23-163.38$ & .002 \\
Renal malperfusion & 12.67 & $2.11-75.97$ & .005 \\
Cerebral malperfusion & 7.10 & $2.08-24.21$ & .002 \\
Extra-anatomic bypass & 9.50 & $3.25-27.81$ & $<.001$ \\
Cardiopulmonary bypass time & 1.01 & $1.00-1.016$ & $<.001$ \\
Coronary malperfusion & 4.50 & $1.00-20.22$ & .050 \\
\hline$O R$, Odion
\end{tabular}

$O R$, Odds ratio; $C I$, confidence interval.

(OR, 12.67; 95\% CI, 2.11-75.97; $P=.005$ ), spinal cord (OR, 22.79; 95\% CI, 2.27-228.97; $P=.008$ ), and viscera (OR, 22.98; 95\% CI, 3.23-163.38; $P=.002$ ); concomitant extra-anatomic bypass (OR, 9.50; 95\% CI, 3.25-27.81; $P<.001$ ); and CPB time $>180$ minutes (OR, $1.01 ; 95 \%$ CI, 1.00-1.016; $P<.001$ ). Coronary malperfusion may also affect operative mortality (OR, 4.50; 95\% CI, 1.00-20.22; $P=.050$; Table 7).

\section{DISCUSSION}

During the past 2 decades, the surgical outcomes of TAAD have improved considerately and various techniques have been proposed for surgical repair. However, the operative mortality has remained high, and several aspects of surgical management remain controversial. The most important issue is the extent of distal aortic repair ${ }^{4-6}$ (ie, the use of a limited approach such as ascending/hemiarch repair $^{6}$ or an extensive approach such as the FET technique $^{8}$ ). Although it has been used more widely, ${ }^{8,10}$ the safety of FET in the acute setting remains debated, ${ }^{24}$ owing to its technical complexity and longer cerebral perfusion and circulatory arrest times, which might increase the risk of mortality and neurologic events. ${ }^{12,13}$ Another important concern is that surgical repair in the acute phase of TAAD was reported to be associated with greater operative mortality than in the chronic phase. ${ }^{1}$ The present study of the early outcomes after the Sun procedure in a large series of 803 patients with acute and chronic TAAD is helpful in addressing these 2 important issues.

First, the present study addressed the issue of the safety of the FET technique in patients with TAAD. The overall operative mortality was $6.5 \%$, and the incidence of stroke and spinal cord injury was $2.0 \%$ and $2.4 \%$, respectively. Except for respiratory morbidities, other postoperative complications such as renal failure, reexploration for bleeding, recurrent nerve injury, and limb ischemia were consistently infrequent, occurring in only $3.3 \%, 3.1 \%$, $1.1 \%$, and $0.9 \%$ of all patients, respectively. These early results have indicated that the Sun procedure is a safe surgical approach for patients with acute and chronic TAAD and will possibly pave the way for wider use of the FET technique. ${ }^{24}$ Moreover, in our previous series of 148 patients with acute TAAD, we achieved a mortality of only $4.7 \%$, which compared favorably with that of a similar group of patients undergoing hemiarch repair, with a mortality of $6.1 \%{ }^{19}$ Uchida and associates ${ }^{9}$ also reported that the FET technique could be performed safely for acute TAAD and might reduce the need for reintervention on the residual false lumen. The results of both studies argue in favor of wider use of the extensive FET when determining the extent of distal repair for patents with TAAD.

Second, although the operative mortality of the Sun procedure was significantly greater in the acute group than in the chronic group $(8.1 \%$ vs $4.3 \%, P=.031)$, multivariate analysis proved that acuity did not affect operative mortality (OR, $1.67 ; 95 \%$ CI, 0.83-3.38; $P=.152)$ in this cohort. This is in agreement with the conclusion of Sabik and colleagues ${ }^{25}$ that the acuity of dissection was not a risk factor for early mortality. In the present series of 803 patients with TAAD, the risk factors for operative mortality after the Sun procedure were previous cerebrovascular disease, malperfusion syndrome (including cerebral, renal, spinal cord, and visceral ischemia), extra-anatomic bypass, and a CPB time $>180$ minutes. These results imply that, in the absence of these risk factors, performing emergency FET with total arch replacement in the setting of acute TAAD will not impose a greater risk of operative mortality compared with an identical procedure performed electively in the setting of chronic TAAD. The present results add evidence that cardiovascular surgeons can safely use this more aggressive FET technique with total arch replacement for cases of acute type A dissections without the fear of worse outcomes for the patient. Because devices and systems are evolving toward an ideal open stent graft, with the accrual of evidence from registry data with longer follow-up, ${ }^{26}$ FET with total arch replacement could become the next standard of care for patients with TAAD for whom arch repair is required. ${ }^{8,15,16,27}$

The results of the present study have shown that FET with total arch replacement is not associated with greater early mortality and morbidity compared with totally conventional techniques. One of the reasons for such favorable outcomes might be the special FET used in this procedure, the Cronus (MicroPort Medical Co, Ltd). It can be implanted very easily and quickly, thereby decreasing the circulatory arrest time, as evidenced by the cerebral perfusion time of $25 \pm 8$ minutes in the present series, which was much shorter than the weighted value of $52 \pm 31$ minutes in the meta-analysis by Tian and associates. ${ }^{10}$ The technical simplicity results in a lower learning curve, which is very important for the wider and quicker spread of this approach in regions with 
large patient populations. The sewing cuffs at the proximal and distal ends make anastomosis easier, which help minimize the risk of proximal endoleak and facilitate manipulations in subsequent operations, should any be required. ${ }^{16}$ An algorithm dictating surgical strategies using our subcategorization of the Stanford system that divides TAAD into subtypes might also have contributed to the better results of the Sun procedure. ${ }^{19}$

Focusing on the effect of patient age on outcome, we failed to identify age as a risk factor for operative mortality, similar to the results of Chiappini and associates. ${ }^{28}$ The most likely reason for this paradoxical finding is the predominance of younger patients in our series, with only 90 of 803 patients $(11.2 \%)$ aged $\geq 60$ years. In contrast, one third of the patients in the International Registry of Aortic Dissection $^{29}$ and $29.9 \%$ in the German Registry for Acute Aortic Dissection Type A were aged $\geq 70$ years. ${ }^{30}$ However, in contemporary FET cohorts, the patients have also been relatively young, with a mean age of 45 to 61 years, irrespective of geographic differences. ${ }^{10,31,32}$ In a group of 355 patients with acute TAAD, Kimura and associates $^{33}$ found that the early and late surgical outcomes were not better in patients aged $\leq 45$ years, with an increased risk of reoperation, possibly because ascending aortic or hemiarch replacement was performed in $>80 \%$ of the patients. Their results conversely imply that the more extensive FET procedure should be chosen for younger patients.

Malperfusion phenomena have an incidence of $16 \%$ to $33 \%$, and clinically apparent malperfusion of any type increases the mortality risk. ${ }^{3,34,35}$ In the present cohort, 4 of the 7 risk factors for operative mortality belonged to malperfusion syndrome, which occurred in 88 patients $(10.9 \%)$ and led to a mortality of $19.3 \%$, with even greater mortality $(25.0 \%)$ in the acute group. Of all malperfusion phenomena, visceral malperfusion is the most lethal, heralding an extremely poor prognosis, ${ }^{3}$ as evidenced by a mortality of $71.4 \%$ ( 5 of 7 ) and a 23 -fold increased risk of death (OR, 22.98). Spinal cord malperfusion carried almost the same risk (OR, 22.79), with a death rate of $50.0 \%$ ( 2 of 4 ). Renal malperfusion often responds well to aortic repair ${ }^{3}$ but increased the risk of death by 12.67 times in the present series, with a mortality of $42.8 \%$ ( 3 of 7 ). With an OR of 4.50 , the effect of coronary malperfusion needs to be further validated in a larger sample with more events $(P=.050)$. The results of the present study have highlighted the malignant effect of malperfusion on the clinical outcome of patients with TAAD. In many patients, malperfusion itself is an indication for aortic repair, which is expected to save life and reperfuse the ischemic organs. In some cases, reperfusion necessitates concomitant procedures, which will inevitably entail longer CPB, crossclamp, and circulatory arrest times, thus forming a vicious cascade of "malperfusion $\rightarrow$ concomitant procedure $\rightarrow$ longer time of $\mathrm{CPB}$, crossclamp, and circulatory arrest $\rightarrow$ higher mortality." This has been corroborated by the results of multivariate analysis, in which malperfusion (of 4 organs), extra-anatomic bypass (to correct malperfusion), and the resultant longer CPB time were all identified as independent risk factors for operative mortality.

The present retrospective study had several limitations. First, $>80 \%$ of our patients had been diagnosed at peripheral or remote hospitals and transferred for a long distance to our institution. Many patients with severe TAAD died of aortic rupture, tamponade, or malperfusion during transfer, while in the emergency room, or even while awaiting surgical repair. Thus, we were treating a group of less severe patients who had survived the initial attack of aortic dissection. Second, our patients were young, with a mean age of 46 years and only $11.2 \%$ of them aged $\geq 60$ years, in contrast to the International Registry of Aortic Dissection $^{29}$ and German Registry for Acute Aortic Dissection Type $\mathrm{A}^{30}$ registries in which $\geq 29.9 \%$ of patients were aged $\geq 70$ years. In the European series, the patients are "all comers," with most of them presenting within the first few hours of dissection. In contrast, only $6.6 \%$ of our patients with acute TAAD presented within the first 10 hours of onset. Therefore, it was very difficult to make direct comparisons between our data and those from Europe and North America. Third, the results of the present study were certainly influenced by the vast experience gained by our group, which is the largest aortic surgical center in China, with an annual case volume of 1100 . Such favorable conditions are not commonly found or replicated elsewhere. Most importantly, data of late survival and freedom from late distal reintervention were limited, and our efforts with long-term follow-up of patients are ongoing.

\section{CONCLUSIONS}

In the present group of patients with TAAD, acuity was not a risk factor for operative mortality of frozen elephant trunk and total arch replacement (the Sun procedure). Patients with previous cerebrovascular disease; malperfusion of the brain, kidneys, spinal cord, and viscera; concomitant extra-anatomic bypass, and longer cardiopulmonary bypass time ( $>180$ minutes) had a greater risk of operative mortality.

\section{References}

1. Safi HJ, Miller CC III, Reardon MJ, Iliopoulos DC, Letsou GV, Espada R, et al Operation for acute and chronic aortic dissection: recent outcome with regard to neurologic deficit and early death. Ann Thorac Surg. 1998;66:402-11.

2. Fann JI, Glower DD, Miller DC, Yun KL, Rankin JS, White WD, et al. Preservation of aortic valve in type A aortic dissection complicated by aortic regurgitation. J Thorac Cardiovasc Surg. 1991;102:62-73; discussion 73-5.

3. Bonser RS, Ranasinghe AM, Loubani M, Evans JD, Thalji NM, Bachet JE, et al Evidence, lack of evidence, controversy, and debate in the provision and performance of the surgery of acute type A aortic dissection. J Am Coll Cardiol. 2011;58:2455-74. 
4. Elefteriades JA. Editorial comment: extended resection in acute type A aortic dissection. Cardiol Clin. 2010;28:349-50.

5. Coady MA, Rizzo JA, Hammond GL, Mandapati D, Darr U, Kopf GS, et al. What is the appropriate size criterion for resection of thoracic aortic aneurysms? J Thorac Cardiovasc Surg. 1997;113:476-91; discussion 89-91.

6. Kim JB, Chung CH, Moon DH, Ha GJ, Lee TY, Jung SH, et al. Total arch repair versus hemiarch repair in the management of acute DeBakey type I aortic dissection. Eur J Cardiothorac Surg. 2011;40:881-7.

7. Ius F, Fleissner F, Pichlmaier M, Karck M, Martens A, Haverich A, et al Total aortic arch replacement with the frozen elephant trunk technique: 10-year follow-up single-centre experience. Eur J Cardiothorac Surg. 2013; 44:949-57.

8. Roselli EE. Trade in the hammer for a power driver-perspectives on the frozen elephant trunk repair for aortic arch disease. Ann Cardiothorac Surg. 2013;2: 633-9.

9. Uchida N, Shibamura H, Katayama A, Shimada N, Sutoh M, Ishihara H. Operative strategy for acute type A aortic dissection: ascending aortic or hemiarch versus total arch replacement with frozen elephant trunk. Ann Thorac Surg. 2009;87:773-7.

10. Tian DH, Wan B, Di Eusanio M, Black D, Yan TD. A systematic review and meta-analysis on the safety and efficacy of the frozen elephant trunk technique in aortic arch surgery. Ann Cardiothorac Surg. 2013;2:581-91.

11. Shrestha M, Pichlmaier M, Martens A, Hagl C, Khaladj N, Haverich A. Total aortic arch replacement with a novel four-branched frozen elephant trunk graft: first-in-man results. Eur J Cardiothorac Surg. 2013;43:406-10.

12. Svensson LG. Device discordancy: lost cords, quick-fix seekers, quality, and ethics. J Thorac Cardiovasc Surg. 2006;131:261-3.

13. Flores J, Kunihara T, Shiiya N, Yoshimoto K, Matsuzaki K, Yasuda K. Extensive deployment of the stented elephant trunk is associated with an increased risk of spinal cord injury. J Thorac Cardiovasc Surg. 2006;131:336-42.

14. Goossens D, Schepens M, Hamerlijnck R, Hartman M, Suttorp MJ, Koomen E, et al. Predictors of hospital mortality in type A aortic dissections: a retrospective analysis of 148 consecutive surgical patients. Cardiovasc Surg. 1998:6:76-80.

15. Ma WG, Zheng J, Liu YM, Zhu JM, Sun LZ. Dr. Sun's procedure for type A aortic dissection: total arch replacement using tetrafurcate graft with stented elephant trunk implantation. Aorta. 2013;1:59-64.

16. Ma WG, Zhu JM, Zheng J, Liu YM, Ziganshin BA, Elefteriades JA, et al. Sun's procedure for complex aortic arch repair: total arch replacement using a tetrafurcate graft with stented elephant trunk implantation. Ann Cardiothorac Surg. 2013;2:642-8.

17. Ma WG, Zheng J, Dong SB, Lu W, Sun K, Qi RD, et al. Sun's procedure of total arch replacement using a tetrafurcated graft with stented elephant trunk implantation: analysis of early outcome in 398 patients with acute type A aortic dissection. Ann Cardiothorac Surg. 2013;2:621-8.

18. Sun LZ, Ma WG, Zhu JM, Zheng J, Liu YM, Ziganshin BA, et al. Sun's procedure for chronic type A aortic dissection: total arch replacement using a tetrafurcate graft with stented elephant trunk implantation. Ann Cardiothorac Surg. 2013;2:665-6.

19. Sun LZ, Qi R, Zhu JM, Liu YM, Chang Q, Zheng J. Repair of acute type A dissection: our experiences and results. Ann Thorac Surg. 2011;91:1147-52.

20. Sun L, Qi R, Zhu J, Liu Y, Zheng J. Total arch replacement combined with stented elephant trunk implantation: a new "standard" therapy for type a dissection involving repair of the aortic arch? Circulation. 2011;123:971-8.

21. Liu ZG, Sun LZ, Chang Q, Zhu JM, Dong C, Yu CT, et al. Should the "elephant trunk" be skeletonized? Total arch replacement combined with stented elephant trunk implantation for Stanford type A aortic dissection. J Thorac Cardiovasc Surg. 2006;131:107-13.

22. Sun LZ, Qi RD, Chang Q, Zhu JM, Liu YM, Yu CT, et al. Surgery for acute type A dissection using total arch replacement combined with stented elephant trunk implantation: experience with 107 patients. J Thorac Cardiovasc Surg. 2009; 138:1358-62.

23. Sun L, Qi R, Chang Q, Zhu J, Liu Y, Yu C, et al. Surgery for acute type A dissection with the tear in the descending aorta using a stented elephant trunk procedure. Ann Thorac Surg. 2009;87:1177-80.

24. Di Eusanio M, Di Bartolomeo R. The Sun procedure-a new paradigm of treatment in DeBakey type 1 acute aortic dissection? Ann Cardiothorac Surg. 2013;2:629-30.

25. Sabik JF, Lytle BW, Blackstone EH, McCarthy PM, Loop FD, Cosgrove DM. Long-term effectiveness of operations for ascending aortic dissections. $J$ Thorac Cardiovasc Surg. 2000;119:946-62.
26. Yan TD, Tian DH, LeMaire SA, Misfeld M, Elefteriades JA, Chen EP, et al The ARCH Projects: design and rationale (IAASSG 001). Eur J Cardiothorac Surg. 2014;45:10-6.

27. Haverich A. Aortic arch replacement with frozen elephant trunk-when not to use it. Ann Cardiothorac Surg. 2013;2:592-6.

28. Chiappini B, Schepens M, Tan E, Dell' Amore A, Morshuis W, Dossche K, et al Early and late outcomes of acute type A aortic dissection: analysis of risk factors in 487 consecutive patients. Eur Heart J. 2005;26:180-6.

29. Trimarchi S, Eagle KA, Nienaber CA, Rampoldi V, Jonker FH, De Vincentiis C, et al. Role of age in acute type A aortic dissection outcome: report from the International Registry of Acute Aortic Dissection (IRAD). J Thorac Cardiovasc Surg. 2010;140:784-9.

30. Rylski B, Hoffmann I, Beyersdorf F, Suedkamp M, Siepe M, Nitsch B, et al. Acute aortic dissection type A: age-related management and outcomes reported in the German Registry for Acute Aortic Dissection Type A (GERAADA) of over 2000 patients. Ann Surg. 2013;96:2129-34.

31. Jakob H, Tsagakis K, Pacini D, Di Bartolomeo R, Mestres C, Mohr F, et al. The International E-vita Open Registry: data sets of 274 patients. J Cardiovasc Surg (Torino). 2011:52:717-23.

32. Roselli EE, Rafael A, Soltesz EG, Canale L, Lytle BW. Simplified frozen elephant trunk repair for acute DeBakey type I dissection. J Thorac Cardiovasc Surg. 2013;145:S197-201.

33. Kimura N, Tanaka M, Kawahito K, Itoh S, Okamura H, Yamaguchi A, et al. Early- and long-term outcomes after surgery for acute type A aortic dissection in patients aged 45 years and younger. Circ J. 2011;75:2135-43.

34. Pacini D, Leone A, Belotti LM, Fortuna D, Gabbieri D, Zussa C, et al. Acute type A aortic dissection: significance of multiorgan malperfusion. Eur J Cardiothorac Surg. 2013;43:820-6.

35. Imoto K, Uchida K, Karube N, Yasutsune T, Cho T, Kimura K, et al. Risk analysis and improvement of strategies in patients who have acute type A aortic dissection with coronary artery dissection. Eur J Cardiothorac Surg. 2013;44:419-25.

\section{Discussion}

Dr Malakh Lal Shrestha (Hannover, Germany). I want to congratulate you on your excellent presentation. Since Hans Borst did the first elephant trunk in 1982 in Hannover, the indications have obviously been expanded.

In 1989, our co-chair of this session, Professor Schäfers, performed the first elephant trunk implantation in acute aortic dissection. Since 2001, we have been doing the same as what you have been doing here, initially as a bailout procedure in the DeBakey type I dissection with intimal tears in the distal arch or proximal descending aorta. However, with more experience, we have also expanded our indications to clinically stable young patients with DeBakey type I dissections even without intimal tears or reentry in the distal arch or descending aorta.

As a high-volume center, what we have learned is that patients with acute and chronic aortic dissection are 2 totally different subsets of patients in terms of clinical presentation and mortality. The greatest danger to the patient with acute aortic dissection is during the first few hours immediately after the dissection, with most patients dying without surgical intervention.

In Germany, owing to the small geographic size compared with the United States and also to excellent emergency services, we receive patients within the first hour, sometimes 2 hours. Even then, when we operate, the mortality is still high. Also, we saw in the Aortic Symposium in New York that the German database shows that in $>3000$ patients, a difference in mortality exists whether you do an ascending aortic replacement or the FET; that is, a $10 \%$ difference, and it was $24 \%$ with FETs.

So, I would like to ask you a couple of questions. First, what is the duration in your case series from the occurrence of dissection 
to surgery? Also, what was the percentage of patients coming within the first few hours?

The second question is, does your series include all comers, or was there some sort of preselection? Because if the patients come later on, whether you operate on them later or the patients are arriving later, it might be in terms of classification acute, but if they come after 4 days, that is a large difference from patients coming in the first day. Thank you.

Dr Ma. Thank you for your comments and questions. You have made inquiries on an important issue of our study. I am not sure if I understood your second question correctly, but I have an answer to your first question.

Please take a look at this table (in slide 6). The first line is the time from the onset of symptoms to the diagnosis. It was $3.2 \pm 3.1$ days on average in the acute group. In the chronic group, the mean time was almost 190 days.

The second line is the duration from diagnosis to surgery. It averaged 2 days, and the median time was 1 day in the acute group. So, most acute patients would have had to wait for 1 day before surgery.

The third line is the time from symptom onset to surgery, which was $5.0 \pm 3.8$ days in the acute group, with a median time of 4 days.

Dr Shrestha. So that means that on the basis of classification, you can still say it is acute. But there has been some sort of "natural selection." So that means, I think at least for the title or the conclusion, you need to qualify the statement saying that no difference exists between acute and chronic, because it is obviously not the same subset of patients that we see in the Western world.

Dr Ma. Yes. Because about $80 \%$ of our patients were referrals, they were transferred from hundreds of miles away or even more remote areas. Therefore, many patients expired on the way to our hospital, in the emergency room, or even while awaiting surgery in the operating room. That is a result of natural selection.

Dr Shrestha. So that means that you would agree with me that in conclusion one cannot say that no difference exists between patients with acute and chronic type A dissection in terms of mortality, right? Because from the onset to surgery was 5 days or 5.5 on average; thus, it was not all comers. So perhaps if you are operating on patients on the first day, that is different than operating on these type of patients?

Dr Ma. Yes. If the patient could be operated on immediately after their arrival at the hospital, the operative mortality might increase.

Dr Shrestha. Thank you.

Dr D. Craig Miller (Stanford, Calif). This was, again, another wonderful presentation by Dr Ma of Dr Sun's vast experience. As I asked Dr Sun a few days ago in New York at the Thoracic Aortic Summit, I continue to be totally flummoxed by why the average age here is 46 , and even younger, for those with acute type A dissection. He answered that this was because of the many patients with severe hypertension. Clearly, they probably have an extremely high incidence of aortic dissection in China.

Respectfully, I still just do not understand this skewing of the population, meaning that the patients that arrive at your center in Beijing are so young. Is it because of economic reasons that the older patients are not being transferred to your hospital or not undergoing surgery? Dr Sun told me in New York that the patients come from 1000, 2000, $3000 \mathrm{~km}$ away. Obviously, a lot of natural selection must be occurring just with a natural piece to the disease. I wonder if an economic selection is also occurring, such that only the younger middle class have the financial resources to reach your center and undergo surgery. I just do not understand why you have an average age that is $\geq 20$ years younger than the European, North American, and South American series of acute type A dissection.

Dr Ma. I think hypertension is a disease related to the change in lifestyles and environment associated with rapid economic development and social alterations. Nowadays, many young people in China smoke tobacco and drink, they are obese and lack physical exercise, and many patients simply do not know they have hypertension at all. Also, even if some people know they have hypertension, their hypertension is not well controlled. Of course, there are many patients with Marfan syndrome or other connective tissue disorders as well. However, many of the elderly in China fortunately did not go through these rapid changes in lifestyle and environment that many young people have to experience. Thus, there are fewer seniors over 60 who suffered from hypertension, which also contributes to the predominance of young patients. I should note that there was no economic factor when we made treatment decisions for the older patients.

Dr Miller. In Japan, they also are very hypertensive, but their age of dissection is older than even in Europe and North America. I simply do not understand this skewed patient population; there must be other factors involved.

But, my main point here today is I think we have to move beyond the fact that "it can be done," which Dr Sun and others have demonstrated. We have to determine which patient with acute type A dissection should undergo distal FET. Should it be just be those with a connective tissue disorder, who probably are at higher risk of late downstream aortic complications? Second, there is no "free lunch" here: we have to justify the increased risk (mainly paraplegia and death) incurred when one does something at the initial operation downstream in the descending aorta. In the large German Registry for Acute Aortic Dissection Type A registry, if the arch was replaced (with or without concomitant FET) electively without a compelling reason to do so, a $10 \%$ increment occurred in the operative mortality rate. So the main questions is whom should it be done in, not just can it be done safely. Does that make any sense to you?

Dr Ma. We have already initiated a study on those young patients 3 years ago and are seeking to identify some genetic causes in those younger patients. Also, we are striving to set up aortic surgical training centers across China, so that patients will not have to travel such a long distance to receive appropriate surgical management. In addition, our colleagues in cardiology and other specialties are trying hard to educate patients to have adequate control of their blood pressure.

Regarding which patients should undergo distal FET, we believe that those patients who are young, who are unlikely to come back for subsequent intervention on downstream aorta, and who are at continuing risk for distal aortic dilation and dissection (such as Marfan syndrome) may benefit most from the Sun operation because of the specifics of the Chinese patient population, their lifestyles, and risk factors. 
Dr Miller. One last question. You have 550 patients with acute and subacute type A dissection; your point that these cases were not chronic dissections (many years after the initiating event) is important. How many of all these cases did not undergo a Sun procedure or distal FET?

Dr Ma. Because most of those patients were transferred from remote or peripheral hospitals, those peripheral or local hospitals might have kept the easier cases and referred those more complicated cases to us. That is 1 point.

Another point is, before 2009, we tended to do simpler operations, such as the hemiarch repair. Let me show you here on this slide (slide 16).

In this group of patients, 148 patients with acute dissection who underwent a Sun operation. The mortality after the Sun operation was $4.7 \%$. In a similar group of 66 patients with acute type A dissection who had a hemiarch repair, the mortality was $6.1 \%$.

Dr Miller. What about today, does anybody not receive a Sun procedure at your center?

Dr Ma. Yes. If a patient with type A dissection does not have any of these 5 indications for the Sun procedure (listed on this slide [slide 7]), this patient will receive a different operation.

Dr Miller. A simpler operation?

Okay. How many of these patients did you have in the same period?

Dr Ma. As far as I can recall, the number was approximately 300. We looked it up in our database last year. There were about 300 such patients.

Dr Miller. So you do both, okay. Some day I will understand why they are so young. Thank you.

Dr Ma. Thank you. 